\title{
Peroneal muscular atrophy with pyramidal features
}

\author{
AE HARDING, PK THOMAS \\ From the Department of Neurological Science, Royal Free Hospital School of Medicine, and the University \\ Department of Clinical Neurology, Institute of Neurology, London, UK
}

SUMMARY Twenty-five cases of peroneal muscular atrophy with pyramidal features from 15 families are described. This disorder has been referred to as hereditary motor and sensory neuropathy (HMSN) type V by Dyck. Onset was usually in the first two decades of life with difficulty in walking. The clinical syndrome superficially resembled that of HMSN types I and II with distal wasting and weakness involving the legs more than the arms. The tendon reflexes in the upper limbs and at the knee tended to be normal or increased but the ankle jerks were often absent. The plantar responses were extensor in 22 patients, absent in two and flexor in one. Increased tone and weakness in the proximal lower limb muscles were found in about $30 \%$ of cases. Mean motor nerve conduction velocity was lower than in normal controls and sensory nerve action potentials were reduced in amplitude or absent in two thirds of the patients studied. Inheritance was autosomal dominant in the majority of families. The disorder was slowly progressive but did not lead to severe disability.

Since the original descriptions of peroneal muscular atrophy by Charcot, Marie and Tooth in $1886,{ }^{12}$ it has been well recognised that occasional patients with the syndrome have extensor plantar responses. This is rare and occurs in less than $5 \%$ of cases in most large series. ${ }^{34}$ The majority of these patients have affected relatives with flexor or absent plantar responses. The explanation for the exceptions is not clear. It has been shown that pyramidal signs may occasionally develop as a result of hypertrophied nerve roots compressing the spinal cord. ${ }^{5}$ Extensor plantar responses are certainly more frequent in the demyelinating or hypertrophic form of CharcotMarie-Tooth disease (hereditary motor and sensory neuropathy (HMSN) type I). ${ }^{3}$ A further possible explanation is that the plantar response can be extremely difficult to assess in the presence of severe foot deformity.

A number of clinical, genetic and electrophysiological studies in recent years have established that peroneal muscular atrophy is not a single disease, but a heterogeneous syndrome. The most common subgroups are HMSN types I and II and the distal form of spinal muscular atrophy. ${ }^{346-9}$

Address for reprint requests: Dr AE Harding, National Hospital for Nervous Diseases, Queen Square, London WC1 3BG

Received 30 August 1983

Accepted 24 September 1983
These disorders were first delineated by Dyck and Lambert in $1968,{ }^{67}$ who also described patients from two families who all had pyramidal signs in the legs as well as peroneal muscular atrophy. The present paper describes the clinical, genetic, and electrophysiological features of 25 patients with this disorder.

\section{Patients and methods}

The index cases studied were seen during a prospective study on the nosology of peroneal muscular atrophy, and also in a survey of patients with hereditary ataxias and paraplegias in south-east England. The methods of ascertainment have been described elsewhere. ${ }^{3}{ }^{10}$ Patients were only considered to have peroneal muscular atrophy with pyramidal features if they came from families in which at least two affected members had extensor plantar responses or, if there were no affected relatives, there was additional evidence of pyramidal tract dysfunction such as increased knee jerks or increased muscle tone in the legs. This series does not include the occasional cases with extensor plantar responses seen in families in which other members had typical HMSN types I or II, or those patients with longstanding hereditary spastic paraplegia who sometimes develop distal amyotrophy. ${ }^{11}$ The typical clinical features of peroneal muscular atrophy with pyramidal features are illustrated by the members of family A (fig 1), which will be described in detail below. The clinical and electrophysiological data obtained from the whole series of cases are summarised in Tables 1 and 2 . 


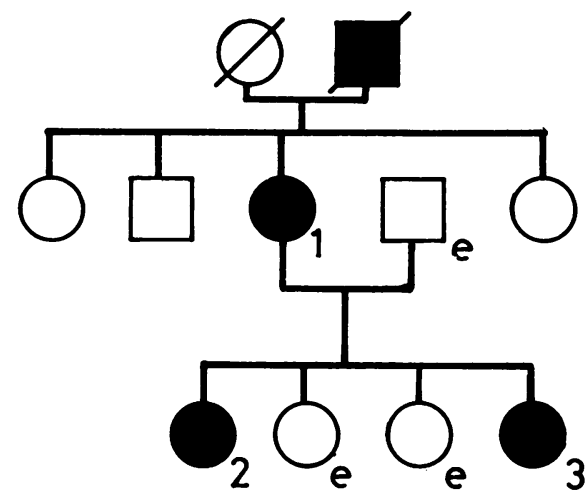

Fig 1 Pedigree of family $A$. (filled symbols = affected, open symbols $=$ unaffected, oblique line $=$ deceased, $e=$ examined, normal; case numbers referred to in text).

\section{Case reports}

Case 1 This 33-year-old woman had no neurological symptoms. On examination there was clawing of the toes and mild weakness of dorsiflexion of the ankles and toes and ankle eversion. All the tendon reflexes were brisk except the ankle jerks which were absent. The plantar responses were extensor. Sensation was normal. Motor nerve conduction velocity in the right ulnar nerve was normal but the ulnar and median sensory action potentials (SAPs) were reduced in amplitude at 6 and $2 \mu \mathrm{V}$ with normal latencies. This patient's father died at the age of 70 years; he had always had high arched feet and a tendency to trip. Her three sibs were stated to be normal but were unavailable for examination.

Case 2 This 14-year-old girl was observed to have difficulty in running from the age of three years and her athletic performance was always poor. On examination the upper limbs were normal. There was bilateral foot drop and pes cavus (fig 2). She had moderate weakness and wasting of the anterior tibial and peroneal muscles, together with the toe extensors. The ankle jerks were absent but the other tendon reflexes were normal. The plantar responses were
Table 1 Clinical features of peroneal muscular atrophy with pyramidal features

\begin{tabular}{|c|c|c|c|c|}
\hline \multicolumn{2}{|c|}{$\begin{array}{l}\text { Presenting symptoms: } \\
\text { Difficulty in walking } \\
\text { Tendency to trip } \\
\text { Foot deformity } \\
\text { Weakness of the hands } \\
\text { Motor delay } \\
\text { Asymptomatic }\end{array}$} & \multicolumn{3}{|c|}{$\begin{array}{l}\text { Number of cases }(\%) \\
10(40) \\
3(12) \\
5(20) \\
3(12) \\
2(8) \\
2(8)\end{array}$} \\
\hline \multirow{2}{*}{\multicolumn{2}{|c|}{$\begin{array}{l}\text { Motor signs: } \\
\text { Distal wasting } \\
\text { mild/moderate } \\
\text { severe } \\
\text { Distal weakness } \\
\text { mild/moderate } \\
\text { severe } \\
\text { Proximal weakness } \\
\text { Increased tone } \\
\text { Ataxia }\end{array}$}} & $\begin{array}{l}\text { Upper limbs } \\
6(24) \\
8(32)\end{array}$ & \multicolumn{2}{|c|}{$\begin{array}{r}12(48) \\
9(36)\end{array}$} \\
\hline & & $\begin{array}{l}6(24) \\
7(28) \\
0 \\
0 \\
2(8)\end{array}$ & \multicolumn{2}{|c|}{$\begin{array}{r}10(40) \\
14(56) \\
7(28) \\
2(8) \\
0\end{array}$} \\
\hline $\begin{array}{l}\text { Tendon reflexes: } \\
\text { Depressed/abs } \\
\text { Normal } \\
\text { Brisk }\end{array}$ & $\begin{array}{l}\text { upper limbs } \\
\text { nt } 5(20) \\
11(44) \\
9(36)\end{array}$ & $\begin{array}{c}\text { knee jerks } \\
5(20) \\
6(24) \\
14(56)\end{array}$ & & $\begin{array}{c}\text { ankle jerks } \\
19(76) \\
5(20) \\
1(4)\end{array}$ \\
\hline $\begin{array}{l}\text { Plantar } \\
\text { responses: }\end{array}$ & $\begin{array}{l}\text { flexor } \\
1 \text { (4) }\end{array}$ & $\begin{array}{l}\text { extensor } \\
22(88)\end{array}$ & & $\begin{array}{c}\text { absent } \\
2 \text { (8) }\end{array}$ \\
\hline $\begin{array}{c}\text { Sensory loss: } \\
\text { upper limbs } \\
\text { lower limbs }\end{array}$ & $\begin{array}{l}\text { VS } \\
0 \\
13(52)\end{array}$ & $\begin{array}{l}\text { JPS } \\
0 \\
4(16)\end{array}$ & $\begin{array}{l}\text { Touch } \\
4\left(\begin{array}{l}16) \\
5(20)\end{array}\right.\end{array}$ & $\begin{array}{l}\text { Pain } \\
3(12) \\
7(28)\end{array}$ \\
\hline $\begin{array}{l}\text { Skeletal deformi } \\
\text { mild/moderate } \\
\text { severe }\end{array}$ & $\begin{array}{l}\text { pes cavus } \\
12(48) \\
6(24)\end{array}$ & $\begin{array}{c}\text { pes planus } \\
1 \\
0\end{array}$ & & $\begin{array}{l}\text { scoliosis } \\
2 \\
0\end{array}$ \\
\hline Gait: & $\begin{array}{l}\text { foot drop } \\
21(84)\end{array}$ & $\begin{array}{l}\text { spastic } \\
5(20)\end{array}$ & & $\begin{array}{c}\text { normal } \\
4(16)\end{array}$ \\
\hline
\end{tabular}

extensor. There was no sensory loss. Motor and sensory conduction studies in the right median nerve were normal, but the right sural SAP was absent. The right extensor digitorum brevis muscle was completely denervated.

Case 3 This six-year-old girl was clinically normal when first examined at the age of 18 months. She was noted to have an abnormal gait and to trip easily when she was five. On examination there was mild pes cavus and weakness of the peroneal and anterior tibial muscles without wasting. The tendon reflexes were normal apart from the ankle

Table 2 Peroneal muscular atrophy with pyramidal features: electrophysiological investigations

\begin{tabular}{|c|c|c|c|}
\hline $\begin{array}{l}\text { Patients } \\
\mathrm{n}= \\
\text { Controls* } \\
\mathrm{n}=\end{array}$ & $\begin{array}{l}\text { Mean motor nerve co } \\
\text { Median } \\
42 \cdot 6 \pm 13 \cdot 0(15-58) \\
16 \\
57 \cdot 2 \pm 4 \cdot 2(52-67) \\
25\end{array}$ & $\begin{array}{l}\text { Ucity } \pm S D \text { (range) } \\
41 \cdot 2 \pm 11.9(19-55) \\
6 \\
56 \cdot 2 \pm 4.6(49-66) \\
46\end{array}$ & $\begin{array}{l}\text { Peroneal } \\
34 \cdot 9 \pm 11 \cdot 9(15-53) \\
11 \\
49 \cdot 7 \pm 7 \cdot 1(36-63) \\
30\end{array}$ \\
\hline \multicolumn{4}{|c|}{${ }^{*}$ from $^{20}$. Mean MNCV significantly less than controls in all three nerves using Student's $t$ test $(p<0.001)$} \\
\hline \multirow{3}{*}{$\begin{array}{l}\text { Median } \\
(n=18) \\
\text { Ulnar } \\
(n=10) \\
\text { Sural } \\
(n=13)\end{array}$} & $\begin{array}{l}\text { Absent } \\
6(33 \cdot 3)\end{array}$ & $\begin{array}{l}\text { Sensory action potentio } \\
\text { number of cases }(\%) \\
\text { Reduced in amplitude } \\
6(33.3)\end{array}$ & $\begin{array}{l}\text { Normal } \\
6(33 \cdot 3)\end{array}$ \\
\hline & $6(60 \cdot 0)$ & $3(30 \cdot 0)$ & $1(10 \cdot 0)$ \\
\hline & $6(46 \cdot 1)$ & $1(7 \cdot 7)$ & $6(46 \cdot 1)$ \\
\hline
\end{tabular}




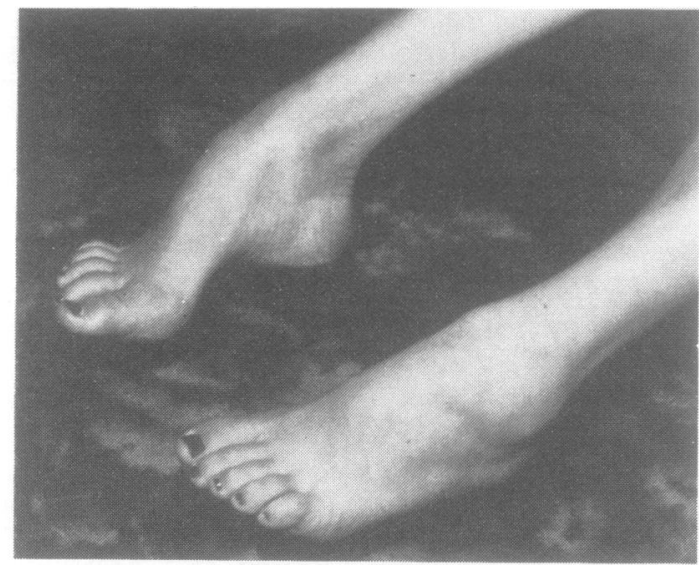

Fig 2 Case 2, showing distal wasting, pes cavus and clawing of the toes.

jerks which were absent. The plantar responses were extensor. Sensation was normal. She walked with bilateral footdrop and a tendency to invert the ankles.

\section{Results}

The 25 patients studied were members of 15 families and inheritance was clearly autosomal dominant in eight of them (fig 1). Another 25 relatives were affected by history but were either dead or unavailable for study. Five patients had no affected relatives; one had been adopted. The parents of one of these were examined and found to be clinically and electrophysiologically normal. In another family two sibs were the only members known to be affected, so inheritance could have been autosomal recessive. Their parents were dead and so could not be examined. There was no known consanguinity between the parents of any of the single generation cases. The ratio of affected males to females was 12:13.

The mean age of the patients at the time of study was $34.4 \pm 20 \cdot 1$ (range 6-74) years. The age of onset was in the first or second decades in the majority of cases, with a median of 10 , mean $11.5 \pm 9.5$ years, ranging from birth to the fourth decade. The most common presenting symptom was of difficulty in walking or running associated with poor athletic performance. Foot deformity was also a common initial complaint. A few patients first noticed wasting of their hand muscles although more profound atrophy was present in the legs. Two were late in first walking. Two patients, aged 33 and 58 years, were asymptomatic and found to be affected on screening family members. The disorder was slowly progressive but varied considerably in severity; even the oldest individual studied, a man aged 74 , was able to walk with a stick.

Distal wasting and weakness in the upper limbs were present in over half of the patients, mostly those with symptoms of long duration. Similar findings in the legs were more frequent, and were most severe in the anterior tibial and peroneal muscles together with the toe extensors. Weakness and wasting were more severe in the arms than in the legs in three patients. Ataxia in the upper limbs was rare. Muscle tone in the legs was normal in most cases but mild spasticity was elicited at the knees in two. Evidence of spasticity was more often obvious when assessing gait but this was not usually marked. Similarly, pyramidal weakness involving the hip and knee flexors occurred in less than half of the patients.

The tendon reflexes were normal or brisk in the arms and at the knee in the majority of cases. Over half had pathologically increased knee jerks. The ankle jerks were absent in most patients and brisk in only one. Only one secondary case had flexor plantar responses. Apart from two patients in whom the plantar reflex was absent, all the rest, including the affected relatives of index cases' had extensor plantar responses.

Sensory loss in the upper limbs was unusual. Vibration sense was commonly lost in the legs and other sensory modalities less frequently so. Sensory testing was entirely normal in about $50 \%$. Pes cavus occurred in three quarters of the patients and was severe in six (fig 2). Pes planus and scoliosis were rare.

Nerve conduction studies were performed in 22 patients. Motor nerve conduction velocity (MNCV) often fell in the normal range but mean MNCV was significantly lower than that of control subjects in the median, ulnar and peroneal nerves (table 2). The small muscles of the hands and feet were completely denervated in three and seven cases respectively. Severely reduced velocities, in one case as low as $15 \mathrm{~m} / \mathrm{s}$ in the median nerve, were usually only seen in patients with marked wasting of the relevant muscles. Sensory action potentials evoked from the median, ulnar and sural nerves were undetectable in about half of the patients studied. They were reduced in amplitude in another third but sensory conduction was entirely normal in five cases. The presence or absence of marked slowing of MNCV and abnormal sensory conduction tended to vary between members of the same family.

\section{Discussion}

Peroneal muscular atrophy with pyramidal features appears to be one of the least common disorders 
giving rise to the peroneal muscular atrophy syndrome. This group of patients constitutes about $5 \%$ of cases investigated in this department in the last 15 years. One of the patients described by Tooth ${ }^{2}$ may have had peroneal muscular atrophy with pyramidal features; a seven-year-old boy was reported to have a "lively knee reflex". The disorder was first identified as a distinct subgroup in two families by Dyck and Lambert in 1968. ${ }^{7}$ The index cases had foot deformity dating back to early childhood. They had distal weakness and wasting in the legs which later involved the upper limbs. The tendon reflexes were normal or brisk in the arms, the knee jerks increased and the ankle jerks depressed with extensor plantar responses. There was mild distal sensory loss to all modalities in the legs. MNCV was normal but SAPs were absent in one case. A small number of similar cases has subsequently been described in large series of patients with peroneal muscular atrophy. ${ }^{8} 9$

The patients reported here superficially resemble those with HMSN types I and II. The range of age of onset and presenting symptoms are very similar, as are the distribution of muscle weakness and type of foot deformity. Nevertheless, there are important clinical differences between HMSN and this syndrome; the present report establishes peroneal muscular atrophy with pyramidal signs as a distinct disease entity. An important clue to the diagnosis of this disorder is a suggestion of spasticity in the patient's gait. This is not present in cases of HMSN. The knee jerks were increased in nearly all the patients reported here, whereas these are absent in 70 and $20 \%$ of cases of HMSN types I and II respectively, and usually depressed in the rest. Extensor plantar responses occur in only $2 \%$ of patients with HMSN type $I$ and are even more rare in type II. $^{3}$ The finding that the presence of extensor plantar responses ran true in all but one of the families investigated in this study implies the presence of a different mutant gene.

Clinically peroneal muscular atrophy with pyramidal features resembles HMSN type II more than type I in several respects. This particularly applies to the upper limbs, where ataxia, tremor, severe weakness and wasting, and areflexia, all of which are common in HMSN type I, are unusual. The degree of sensory loss also resembles that seen in type II HMSN, being less severe than in type I cases, although pain and touch appreciation was not as commonly impaired in the present series as it is in HMSN type II. The frequency and severity of foot deformity found in peroneal muscular atrophy with pyramidal signs were similar to the findings in HMSN type I, which probably reflects the early onset of both disorders compared to HMSN type II.
It should be stressed that peroneal muscular atrophy with pyramidal features is quite distinct from the Strümpell type of "pure" hereditary spastic paraplegia. Dyck ${ }^{12}$ has implied that they are the same disease but there are compelling reasons for suggesting that this is not so. Spasticity in the lower limbs is much more severe in hereditary spastic paraplegia (HSP) and distal weakness and wasting not explicable on the basis of combined pyramidal deficit and disuse are rare. ${ }^{11}{ }^{13}$ Some patients with hereditary "pure" spastic paraplegia do develop neurogenic atrophy of the small hand muscles, but this is a late manifestation of the disease which does not run true within families and the lower limbs appear to be spared. Similarly, the ankle jerks are usually pathologically increased and associated with clonus in HSP apart from in occasional cases of long duration. ${ }^{11}$

Sensation is often normal in HSP, but some patients develop loss of vibration sense and occasionally of proprioception. Appreciation of touch and pain is normal, which is not always the case in peroneal muscular atrophy with pyramidal features. Although somatosensory evoked potentials may be abnormal in HSP, peripheral sensory conduction has been reported as normal in a number of studies. ${ }^{11} 1415$ The majority of patients in the present series, and those reported by other authors, had small or absent sensory action potentials.

There have been few reports of peripheral nerve histology in either disorder. Qualitative studies suggest that it is normal in HSP. ${ }^{16}$ Dyck $^{12}$ has reported loss of large myelinated fibres in older patients but it is not clear whether they had HSP or peroneal muscular atrophy with pyramidal features. Behse and Buchthal ${ }^{17}$ found a slight loss of large myelinated fibres and some clusters of regenerating fibres in two out of five patients stated to have "hereditary spastic paraplegia with peroneal muscular atrophy". These changes were not as severe as those seen in HMSN type II. It at least appears that involvement of the primary sensory neuron occurs in most cases of peroneal muscular atrophy with pyramidal features and very few of HSP. A further point in favour of the separation of these two disorders is that they do not occur together in individual families.

The occasional finding of normal sensory nerve conduction or severe slowing of motor nerve conduction velocity in this series raises the question as to whether peroneal muscular atrophy with pyramidal features is itself heterogeneous. This would seem unlikely, as a member of one family had normal sensory nerve conduction whereas other affected relatives did not. Motor nerve conduction velocity also varied within families (from 19 to 48 $\mathrm{m} / \mathrm{s}$ in different members of one). It was felt that 
some of the slowest velocities observed were at least partly due to fall out of fast conducting fibres, as they tended to occur in patients with severe muscle wasting. This issue can only be clarified by appropriate histological studies.

The pedigree data obtained in this study suggest that peroneal muscular atrophy with pyramidal features is of autosomal dominant inheritance in the majority of cases. The parents of most of the single cases and the two affected sibs could not be examined; as two other patients were asymptomatic but affected it is quite possible that inheritance was dominant in some of these families with limited expression in the parents. The parents of one single case were clinically and electrophysiologically normal. The disease may either have been of autosomal recessive inheritance in this patient or due to a fresh dominant mutation.

In terms of classification, Dyck ${ }^{12}$ has allocated peroneal muscular atrophy with pyramidal features to the hereditary motor and sensory neuropathies (HMSN type V). This implies involvement of the primary sensory neuron which is not present in all patients. A case can also be made for classifying this disorder amongst the complicated forms of HSP associated with amyotrophy, of which there are at least six types. ${ }^{10}$ These include the syndrome of spastic paraplegia and selective wasting of the small hand muscles described by Silver, ${ }^{18}$ the Troyer syndrome $^{19}$ and others. ${ }^{10}$

Peroneal muscular atrophy with pyramidal features is rare, but should be identified as a distinct disorder. It is a relatively benign condition which does not appear to shorten life expectancy or lead to severe disability. Recognition of this syndrome demonstrates yet again the clinical and genetic heterogeneity of peroneal muscular atrophy.

We thank Mr A Catterall, Drs FG Campbell, NR Dennis and RM Winter for referring patients, and the Friedreich's Ataxia Group for financial support.

\section{References}

${ }^{1}$ Charcot JM, Marie P. Sur une forme particulière d'atrophie musculaire progressive, souvent familiale débutant par les pieds et les jambes et atteignant plus tards les mains. Rev Méd (Paris) 1886;6:97-138.

${ }^{2}$ Tooth HH. The peroneal type of progressive muscular atrophy. London: HK Lewis, 1886.

${ }^{3}$ Harding AE, Thomas PK. The clinical features of hereditary motor and sensory neuropathy types I and II. Brain 1980;103:259-280.
4 Davis CJF, Bradley WG, Madrid R. The peroneal muscular atrophy syndrome. (Clinical, genetic, electrophysiological and nerve biopsy studies). J Gérvét Hum 1978;26:311-49.

5 Symonds CP, Blackwood W. Spinal cord compression in hypertrophic neuritis. Brain 1962;85:251-60.

- Dyck PJ, Lambert EH. Lower motor and primary sensory neuron diseases with peroneal muscular atrophy. I. Neurologic, genetic and electrophysiologic findings in hereditary polyneuropathies. Arch Neurol 1968;18:603-18.

7 Dyck PJ, Lambert EH. Lower motor and primary sensory neuron diseases with peroneal muscular atrophy. II. Neurologic, genetic and electrophysiologic findings in various neuronal degenerations. Arch Neurol 1968;18:619-25.

${ }^{8}$ Buchthal F, Behse F. Peroneal muscular atrophy and related disorders. I. Clinical manifestations as related to biopsy findings, nerve conduction and electromyography. Brain 1977;100:41-66.

9 Brust JCM, Lovelace RE, Devi S. Clinical and electrodiagnostic features of Charcot-Marie-Tooth syndrome. Acta Neurol Scand 1978;58: suppl 68:1-142.

${ }^{10}$ Harding AE. Classification of the hereditary ataxias and paraplegias. Lancet 1983;i:1151-5.

"Harding AE. Hereditary "pure" spastic paraplegia: a clinical and genetic study of 22 families. J Neurol Neurosurg Psychiatry 1981;44:871-83.

12 Dyck PJ. Inherited neuronal degeneration and atrophy affecting peripheral motor, sensory and autonomic neurons. In: Dyck PJ, Thomas PK and Lambert EH eds. Peripheral Neuropathy. Philadelphia: WB Saunders, 1975:825-67.

${ }^{13}$ Garland HG, Astley CE. Hereditary spastic paraplegia with amyotrophy and pes cavus. J Neurol Neurosurg Psychiatry 1950;13:130-3.

14 McLeod JG, Morgan JA, Reye C. Electrophysiological studies in familial spastic paraplegia. J Neurol Neurosurg Psychiatry 1977;40:611-5.

15 Thomas PK, Jefferys JGR, Smith IS, Loulakakis D. Spinal somatosensory evoked potentials in hereditary spastic paraplegia. J Neurol Neurosurg Psychiatry 1981;44:243-6.

${ }^{16}$ Behan WMH, Maia M. Strümpell's familial spastic paraplegia: genetics and neuropathology. J Neurol Neurosurg Psychiatry 1974;37:8-20.

${ }^{17}$ Behse F, Buchthal F. Peroneal muscular atrophy (PMA) and related disorders. II. Histological findings in sural nerves. Brain 1977;100:67-85.

${ }^{18}$ Silver JR. Familial spastic paraplegia with amyotrophy of the hands. J Neurol Neurosurg Psychiatry 1966;29:135-44.

${ }^{19}$ Cross HE, McKusick VA. The Troyer syndrome. A recessive form of spastic paraplegia with distal muscle wasting. Arch Neurol 1967;16:473-85.

${ }^{20}$ Thomas PK, Sears TA, Gilliatt RW. The range of conduction velocity in normal motor nerve fibres to the small muscles of the hand and foot. J Neurol Neurosurg Psychiatry 1959;22:175-81. 